\title{
Quantitative assessment of direct and indirect landslide risk along transportation lines in southern India
}

\author{
P. Jaiswal ${ }^{1,2}$, C. J. van. Westen ${ }^{2}$, and V. Jetten ${ }^{2}$ \\ ${ }^{1}$ Geological Survey of India (GSI), Bandlaguda, Hyderabad, Andhra Pradesh, India \\ ${ }^{2}$ ITC, University of Twente, Hengelosestraat 99, 7514 AE, Enschede, The Netherlands
}

Received: 15 January 2010 - Revised: 28 April 2010 - Accepted: 11 May 2010 - Published: 17 June 2010

\begin{abstract}
A quantitative approach for landslide risk assessment along transportation lines is presented and applied to a road and a railway alignment in the Nilgiri hills in southern India. The method allows estimating direct risk affecting the alignments, vehicles and people, and indirect risk resulting from the disruption of economic activities. The data required for the risk estimation were obtained from historical records. A total of 901 landslides were catalogued initiating from cut slopes along the railway and road alignment. The landslides were grouped into three magnitude classes based on the landslide type, volume, scar depth, run-out distance, etc and their probability of occurrence was obtained using frequency-volume distribution. Hazard, for a given return period, expressed as the number of landslides of a given magnitude class per kilometre of cut slopes, was obtained using Gumbel distribution and probability of landslide magnitude. In total 18 specific hazard scenarios were generated using the three magnitude classes and six return periods $(1,3,5$, 15,25 , and 50 years). The assessment of the vulnerability of the road and railway line was based on damage records whereas the vulnerability of different types of vehicles and people was subjectively assessed based on limited historic incidents. Direct specific loss for the alignments (railway line and road), vehicles (train, bus, lorry, car and motorbike) was expressed in monetary value (US\$), and direct specific loss of life of commuters was expressed in annual probability of death. Indirect specific loss (US\$) derived from the traffic interruption was evaluated considering alternative driving routes, and includes losses resulting from additional fuel consumption, additional travel cost, loss of income to the local business, and loss of revenue to the railway department. The results indicate that the total loss, including both direct and indirect loss, from 1 to 50 years return period, varies from
\end{abstract}

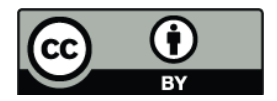

Correspondence to: P. Jaiswal (jaiswal@itc.nl)
US\$90 840 to US\$779 500 and the average annual total loss was estimated as US\$35000. The annual probability of a person most at risk travelling in a bus, lorry, car, motorbike and train is less than $10^{-4}$ /annum in all the time periods considered. The detailed estimation of direct and indirect risk will facilitate developing landslide risk mitigation and management strategies for transportation lines in the study area.

\section{Introduction}

Landslide risk can be defined as the expected number of lives lost, persons injured, damage to properties and disruption of economic activities due to landslides for a given area and reference period (Varnes, 1984). This definition of landslide risk is very appropriate for a transportation line where the risk is both direct, affecting the alignment itself or vehicles and people, and indirect, disrupting economic activities. Direct risks are the cost for restoration and repair of infrastructure, damages to vehicle and loss of lives, whereas indirect risk affects the society by disrupting the utility services and local businesses, thereby incurring loss of revenue, tourism and increase in cost of day to day commodities (van Westen et al., 2006).

Landslides that occur on cut slopes along transportation lines such as roads and railway lines are generally small in size but can occur with a high frequency (Dai and Lee, 2001; Luino, 2005) and present a risk to life and property. The risk can be calculated either individually for one specific type of landslide and one specific element at risk, or by integrating all types of landslides and elements at risk giving the total risk. The quantitative analysis of risk requires estimation of the frequency of landsliding (hazard) and the degree of loss to specific elements at risk resulting from the specified landslide magnitude (van Westen et al., 2006). The calculation of risk further requires analysis of the spatial and temporal probabilities that a given element at risk is hit by a landslide of a particular type and magnitude (Fell et al., 2008). This

Published by Copernicus Publications on behalf of the European Geosciences Union. 
concept of landslide risk is well documented and several publications are available that deal with the concepts and possible methods to carry out risk analysis (e.g. Guzzetti, 2000; Dai et al., 2002; van Westen et al., 2006; Fell et al., 2008), but the number of publications on the actual implementation of spatial landslide risk estimation in specific cases is still rather modest. The lack of publication on case studies of risk estimation is either due to the unavailability of data for the quantitative assessment of hazards for landslides on mapping scales smaller than 1:5000 (van Westen et al., 2006), or due to the lack of a uniform methodology for the assessment of the vulnerability of elements at risk (Glade and Crozier, 2005). The estimation of risk becomes further complicated in many countries due to the insufficient historical records on landslides, unavailability of data on past losses and the uncertainty in the assessment of indirect risks. The estimation of indirect risk is difficult because the loss is not only site specific but affects a larger part of the area far beyond the actual place where the physical damage has taken place (Remondo et al., 2008). The cumulative effect of indirect loss includes all types of losses such as economic loss, social loss and emotional loss. Such loss is often not directly visible to the society but studies have indicated that if it is estimated realistically then the resulting economic loss would be higher than the direct loss (Schuster and Fleming, 1986; Zezere et al., 2007).

Recently, a number of attempts have been made to quantify direct landslide risk along transportation lines (e.g. Bunce et al., 1997; Hungr et al., 1999; Budetta, 2002; Guzzetti et al., 2004; Wilson et al., 2005; Zezere et al., 2007) and indirect risks due to the blockage of roads and railways (e.g. Remondo et al., 2008; Zezere et al., 2007; Bonachea et al., 2009). Hungr et al. (1999) have used the magnitude-frequency curves of rock falls to assess their direct impact on a moving vehicle. Some researchers have used the "event tree" analysis for risk quantification (Bunce et al., 1997; Budetta, 2002). In the event tree approach an occurrence probability is assigned to each event in a sequence which could lead to a landslide fatality. Some researchers have used annual probability of landslide hazard and related consequences to estimate both direct and indirect risk due to a landslide (Zezere et al., 2007; Remondo et al., 2008). They estimated consequences as a product of vulnerability and the value of elements at risk.

In all risk studies the assessment of vulnerability of elements at risk remains a difficult task. Along transportation lines the elements at risk can either be static such as the alignment itself or dynamic such as commuters and moving vehicles. Their vulnerability depends on many factors, including: (a) type and size of the landslide, (b) type of infrastructure, (c) speed and type of vehicles, and (d) physical condition of commuters (Wilson et al., 2005). These factors are often difficult to quantify due to the scarcity of good damage records and therefore, in most studies, the assessment of vulnerability remains somewhat subjective (Dai et al., 2002).
After the quantification of risk, the estimated risk is evaluated in terms of its associated social, economic and environmental consequences, and finally the risk assessment is carried out by comparing the output of the risk analysis against values of judgments and risk tolerance criteria to determine if the risks are low enough to be tolerable (Fell et al., 2005). The judgment takes into account the political, legal, environmental, regulatory and societal factors. In some countries, the limit of the tolerable risk for person most at risk is specified (e.g. AGS, 2000) but, there are no universally established individual risk acceptance criteria and the limits of tolerable risk may vary from country to country (Fell et al., 2005).

In this paper we estimated both direct and indirect risks due to landslides originating from cut slopes along a road and a railway line in the Nilgiri hills of Tamilnadu, India. The landslide hazard descriptor, as recommended by Joint Technical Committee on landslides and Engineered Slopes, JTC-1guidelines (Fell et al., 2008), expresses hazard along a transportation line as the number of landslides of a given magnitude per annum per kilometre of cut slopes. We used this definition in our analysis and have tried to quantify it based on historical information. The data required for the risk assessment were obtained from historical records.

\section{The study area}

The risk assessment was carried out along two transportation lines: a $17-\mathrm{km}$ long section of a railway line, and a $24-\mathrm{km}$ long section of a road (Fig. 1). The road is a national highway (NH-67) and the railway line was declared a world heritage route by UNESCO because of its unique "rack and pinion" rail structure and use of steam engine. Both form part of the main transportation lines connecting Mettupalayam to Coonoor in the state of Tamilnadu in southern India.

The road and the railway line are cut through soil and laterite, underlain by charnockite and garnetiferrous quartzofelspathic gneisses belonging to the Charnockite Group of the Archaean age (Seshagiri and Badrinarayanan, 1982).

The land use surrounding the road and the railway is either forest reserve or tea plantation. Settlements are sparse with Burliyar (560 inhabitants) and Katteri (370 inhabitants) the two major commercial and residential settlements located along the road (see Fig. 1).

A detailed inventory for landslides on cut slopes was prepared from available historical records such as railway maintenance register (locally called "railway slip register"), a summary table of landslides along the railway line and technical reports. Data on 901 landslides were compiled from the historical records covering a 21-year period from 1 January 1987 to 31 December 2007. Out of the 901 landslides, 565 landslides $(63 \%)$ were obtained from railway slip registers (from 1992 to 2007), 220 (24\%) from railway landslide tables (from 1987 to 1991) and 116 (13\%) from technical reports (from 1987 to 2007). The landslides are 


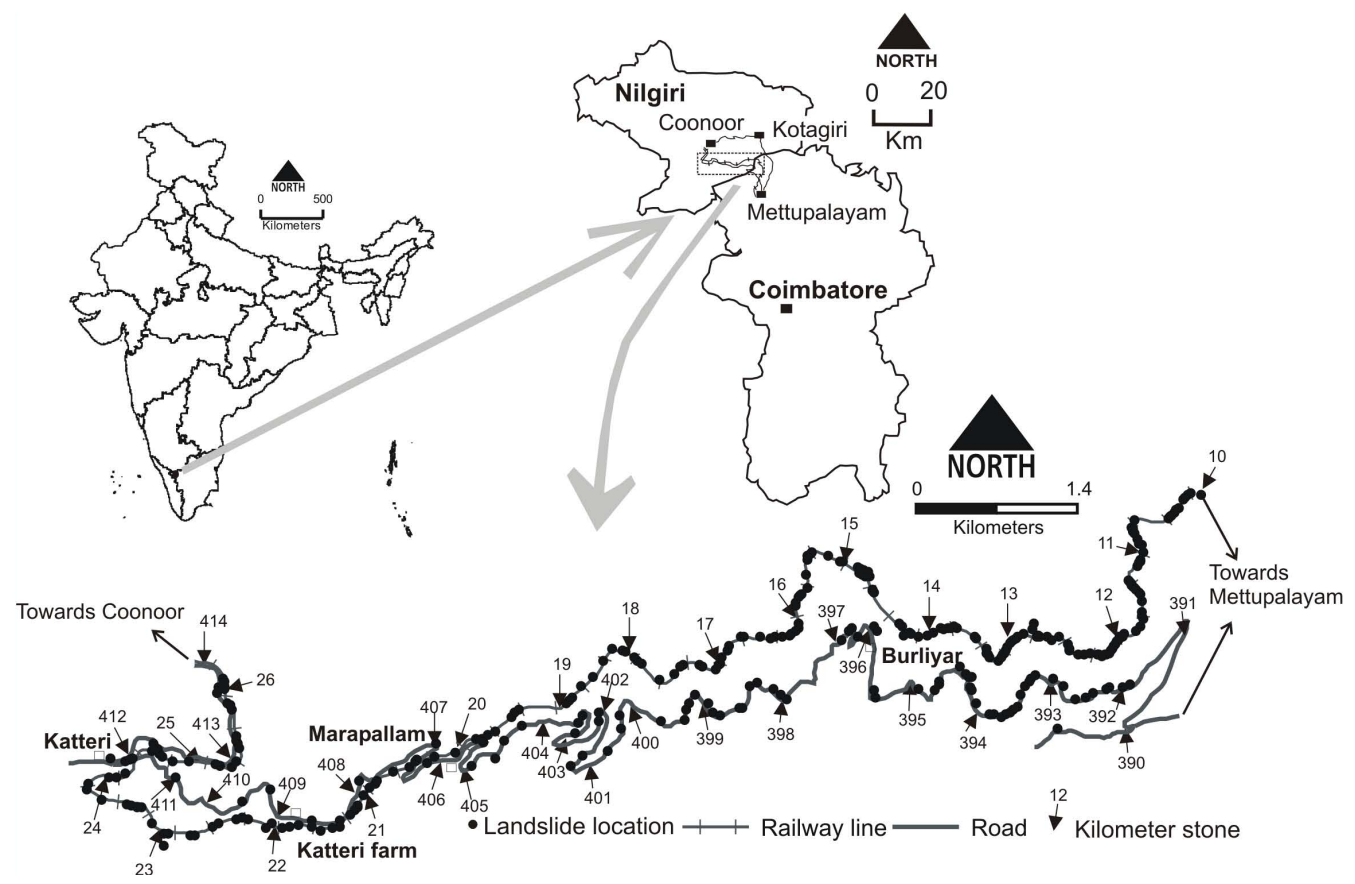

Fig. 1. Location of the road and the railway alignment. Black circles are the location of landslides.

shallow translational debris slides mostly triggered by retreating monsoon rainfall during the period from October to December (Jaiswal and van Westen, 2009). The location of landslides along the railway line and the road is shown in Fig. 1. Figure 2 shows an example of the type of debris slides on cut slopes along the road (A-C) and the railway line (DE). Along the railway line, landslide volume ranges from 2 to $3600 \mathrm{~m}^{3}$ (average $\sim 93 \mathrm{~m}^{3}$ and median $\sim 20 \mathrm{~m}^{3}$ ) and along the road it ranges from 2 to $5300 \mathrm{~m}^{3}$ (average $\sim 360 \mathrm{~m}^{3}$ and median $\sim 160 \mathrm{~m}^{3}$ ). Landslides on natural slopes are very few ( $<35$ slides) and all are first time failures located upslope of the railway line and the road.

Landslides on cut slopes were individually small in size but occurred in a large number and caused substantial damage to the road and the railway property. Landslides occur both as a first time failure or reactivated failures. Figure 2a shows a temporal evolution of landslides on a cut slope near Katteri where the old scar belongs to the 1979 landslide event and within the old scar new landslides have occurred in 2006 and 2007. Along the railway line even small landslides have caused severe damage to the railway alignments. Figure $2 \mathrm{e}$ shows debris slides that affected tunnel portal and destroyed the railway track. The railway company on average had to spend about US\$83000 each year for restoring the railway line due to damages caused by landslides. The number of recorded landslides from cut slopes along the road is relatively less than the railway line. The relative lack of data along the road might be due to the fact that smaller landslides are not reported as they do not cause damage to the road itself.

\section{Method for landslide risk analysis}

In this study both direct and indirect landslide risk was analyzed. To assess direct risk to the physical infrastructural components (features of the railway line and road), vehicles and commuters, the following activities are required (Fell et al., 2008):

1. assessment of landslide hazard for slides from cut slopes,

2. quantification of elements at risk, including persons and property potentially affected by landsliding,

3. assessment of temporal probability of the elements at risk to be in an exposed position,

4. assessment of probability of the landslide reaching the elements at risk, and

5. assessment of the vulnerability of the elements at risk, in terms of property damage (monetary loss) or loss of life.

The assessment of indirect risk depends on the socioeconomic condition of the area of interest. It requires determination of the most important elements and activities in the area and how they could be affected due to the disruption (Remondo et al., 2008). The elements that are indirectly affected due to the traffic disruption include local businesses, residents, tourists, and transport and railway department. 

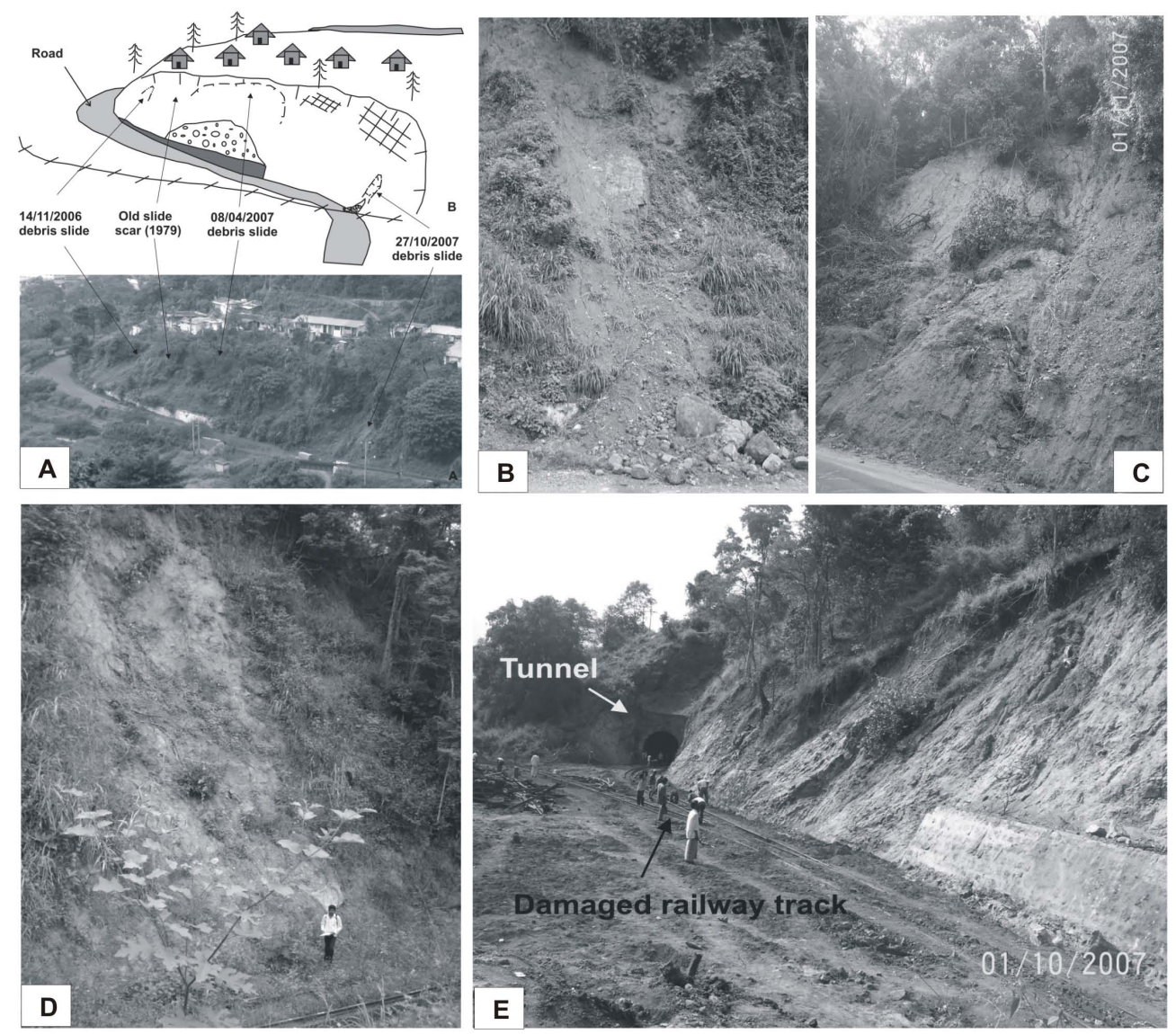

Fig. 2. Landslides on cut slopes along the road (A-C) and the railway line (D-E). Black arrow indicates the position of the railway track which was completely damaged (E).

As a first step of the risk analysis, specific risk is estimated individually for each element at risk for a specific landslide hazard and then total risk is calculated by adding all the specific losses of both direct and indirect risks, separately for the property loss and the loss of life.

\section{Assessment of landslide hazard}

To calculate hazard we first estimated the total number of landslides per kilometre for different return periods. This was multiplied by the probability that the landslides belong to a given magnitude class. This gives hazard for a given return period expressed as the number of landslides of a given magnitude class per kilometre of cut slopes.

The number of landslides per kilometre was estimated for different return periods using the Gumbel distribution model (Gumbel, 1958). Input was taken as the total number of landslides per kilometre of road or railway line per year. The model establishes a relationship between the number of landslides and return period, which on inverse gives the annual probability. The model predicts to a return period in the future depending on the length of the available time series. Ideally, it should not exceed twice the length of the time series.
In the literature other methods such as Poisson and Binomial distribution models are commonly used for estimating the annual exceedance probability (AEP) of landslides i.e. the probability of experiencing one or more landslides during any given time (e.g. Coe et al., 2000; Guzzetti et al., 2005). The Poisson and Binomial models provide an estimate of the probability of experiencing at least one or more landslides and not the specific number of landslides. The specific number of landslides is required if an estimate of both direct and indirect risk along a transportation line is to be made. The number of landslides is required to estimate the probability of a landslide hitting a vehicle and the blockage time of a transportation line by computing the total volume of debris, and therefore an estimate of "at least one landslide" is not enough. The frequency of landslides and the annual probability (return period) can be obtained using statistical model such as Gumbel extreme value distribution.

Along the railway line, Gumbel analysis was carried out for each kilometre, producing 17 plots, one for each kilometre of the $17 \mathrm{~km}$ of railway line. The process used to obtain the Gumbel plots along with an example is given in Jaiswal et al. (2010). Along the road, landslide data were not available for every kilometre length and therefore the Gumbel 
Table 1. Magnitude class for landslides on cut slopes.

\begin{tabular}{lcccccc}
\hline Size class & $V$, range $\left(\mathrm{m}^{3}\right)$ & $S_{\mathrm{d}}(\mathrm{m})$ & $\mathrm{RD}(\mathrm{m})$ & $A_{\mathrm{d}}(\mathrm{m})$ & \multicolumn{2}{c}{$P$, range (average) } \\
\cline { 6 - 7 } & & & & & $<100$ slides/year & $\geq 100$ slides/year \\
\hline M-I & $<10^{2}$ & $<1$ & $<10$ & 1 & $0.5-1(0.85)$ & 0.39 \\
M-II & $10^{2}-10^{3}$ & $<2$ & $10-50$ & $<2$ & $0.01-0.33(0.13)$ & 0.53 \\
M-III & $>10^{3}$ & $2-8$ & $>50$ & $<5$ & $0-0.16(0.02)$ & 0.08
\end{tabular}

$V$ is the volume of landslide at source, $S_{\mathrm{d}}$ is depth of scar, RD is run-out distance, $A_{\mathrm{d}}$ is depth of accumulated debris, and $P$ is probability of occurrence.

analysis was performed on two sections: a section with a length of $10 \mathrm{~km}$ (SI from km-390 to km-400), and a section of 14-km length (SII from km-400 to km-414). The two sections were selected on the basis of the difference in lineal frequency of landslide scars, or the percentage of the length the road with landslide scars on cut slopes adjacent to the road. In section SI, the average lineal frequency per kilometre is $14 \%$, which is about three times higher than section SII at $5 \%$. The average landslide lineal frequency per kilometre for the entire road is about $9 \%$. The total number of landslides in a year per section of the transportation lines was obtained from the landslide catalogue covering the 21-year period from 1987 to 2007 . During this period, the railway line was affected by 785 landslides of which the lowest number was recorded along km-26 (14landslides) and the highest along km-12 (101 landslides). The maximum number of landslides for any kilometre length in a year was recorded in 2006 (25 landslides along km-11). During the period from 1987 to 2007 the road was affected by 116 landslides with an average of 4.8 landslides per kilometre. From the Gumbel distributions, the yearly values pertaining to the number of landslides for the 21-years period were ranked from low to high. For each section of the road and the railway line the number of landslides expected in 1, 3, 5, 15, 25, and 50 years return period were then estimated.

The results indicate that no landslide is expected to occur along the railway line and the road on average once every year. Total 56, 84, 140, 164, and 197 landslides are expected to occur along the railway line and 14, 28, 55, 66, and 82 landslides are expected along the road in $\mathrm{T}_{3}, \mathrm{~T}_{5}, \mathrm{~T}_{15}, \mathrm{~T}_{25}$ and $\mathrm{T}_{50}$ years return period, respectively. A four kilometre stretch of the railway line (from km-10 to $\mathrm{km}-13$ ) is more prone to landslides, as is the $10-\mathrm{km}$ section of road from $\mathrm{km}$ 390 to $\mathrm{km}-400$.

The probability of landslide magnitude was obtained using the catalogue prepared from the railway slip register, which contains information on the volume, spatial and temporal distribution of landslide debris on the railway line since 1992. During the period from 1992 to 2007, single rainstorms caused at least six landslides in 1994 and a maximum of 88 landslides in 2006 along the railway line. The range and frequency of landslide volumes in each year was different and is attributed to differences in rainfall duration and frequency. For the probability calculation, we grouped all landslides into three magnitude classes (i.e. M-I, M-II and M-III) based on debris volume. Data on other characteristics such as scar depth, run-out distance, etc were also collated (Table 1). The probability of occurrence of landslides of a given magnitude class was estimated using the volume-frequency distribution. The frequency of landslides (percentage) in each magnitude class was taken as the probability of occurrence and this was calculated for each year from 1992 to 2007 . We decided to use two sets of probabilities for years with more than and less than 100 landslides, because the event inventories indicate that if rainfall triggers less than 100 landslides in a year then the majority $(>55 \%)$ have volumes less than $100 \mathrm{~m}^{3}$. These are the events that occur more frequently and are associated with lower rainfall intensity and trigger more small landslides. For events resulting more than 100 landslides (e.g. 14 November 2006), a larger proportion of the catalogue consists of landslides with volumes greater than $100 \mathrm{~m}^{3}$. Such events occur less frequently but due to greater rainfall intensity they trigger more landslides with larger volumes. For years during which less than 100 landslides occurred, the annual probability of occurrence of landslides belonging to magnitude class M-I varied from 0.5 to 1 (average $=0.85$ ), for magnitude class M-II from 0.01 to 0.33 (average 0.13 ) and for magnitude class M-III from 0 to 0.16 (average $=0.02$ ). For years with more than 100 landslides the following probability values were used: 0.39 for class M-I, 0.53 for class M-II and 0.08 for class MIII (see Table 1). The largest landslide recorded along the railway line had a volume of $\sim 3600 \mathrm{~m}^{3}$ and along the road the largest landslide had a volume of $\sim 5250 \mathrm{~m}^{3}$.

For a hazard calculation the probability value for the given magnitude class was taken depending on the total number of landslides along the transportation lines in the given return period. In total 18 specific hazard scenarios were generated using combinations of the three magnitude classes and six return periods $\left(\mathrm{T}_{1}, \mathrm{~T}_{3}, \mathrm{~T}_{5}, \mathrm{~T}_{15}, \mathrm{~T}_{25}\right.$ and $\mathrm{T}_{50}$ years). For $\mathrm{T}_{1}$ year return period the transportation lines have zero hazard because no landslide is expected with one year return time. 
Table 2. Landslide hazard along the railway line in $\mathrm{T}_{50}$ years return period.

\begin{tabular}{lccc}
\hline \multirow{2}{*}{$\mathrm{km}$} & \multicolumn{3}{c}{ \# landslides/km } \\
\cline { 2 - 4 } & H-I & H-II & H-III \\
\hline 10 & 8.2 & 11.2 & 1.7 \\
11 & 10.1 & 13.7 & 2.1 \\
12 & 8.9 & 12.2 & 1.8 \\
13 & 7.1 & 9.7 & 1.5 \\
14 & 4.7 & 6.5 & 1.0 \\
15 & 4.8 & 6.5 & 1.0 \\
16 & 4.1 & 5.6 & 0.9 \\
17 & 3.8 & 5.2 & 0.8 \\
18 & 3.3 & 4.5 & 0.7 \\
19 & 2.7 & 3.7 & 0.6 \\
20 & 2.6 & 3.5 & 0.5 \\
21 & 2.8 & 3.7 & 0.6 \\
22 & 3.4 & 4.6 & 0.7 \\
23 & 2.7 & 3.7 & 0.6 \\
24 & 2.8 & 3.7 & 0.6 \\
25 & 2.5 & 3.4 & 0.5 \\
26 & 2.2 & 2.9 & 0.4 \\
Total & 76.7 & 104.3 & 16 \\
\hline
\end{tabular}

H-I, H-II and H-III are the specific hazard related to landslide of M-I, M-II and M-III, respectively.

An example of three specific hazard scenarios for $\mathrm{T}_{50}$ years return period as estimated per kilometre length of the railway line and the road is given in Tables 2 and 3, respectively. The hazard categories H-I, H-II and H-III show the number of landslides of magnitude class M-I, M-II and MIII, respectively that occurs per kilometre of the cut slopes. The tables indicate that on average once in 50 years (annual probability of 0.02 ) the entire railway line will be affected by $76.7,104.3$, and 16 landslides and the road by $32,43.4$, and 6.6 landslides of H-I, H-II and H-III hazard, respectively.

\section{Estimation of direct risk}

Direct risk was estimated for elements that can be directly affected by landslides along the transportation lines, such as the physical infrastructural components (components of the railway line and road), vehicles (trains, buses, trucks, cars and motorbikes), and people (road and train users).

\subsection{Direct risk to the infrastructure components}

For the calculation of the direct risk to the infrastructure components, the following equation was used (adapted from Fell et al., 2005):

$\mathrm{RD}_{\mathrm{EaR}}=\sum_{m=1}^{m=n}\left(H_{\mathrm{m}} \cdot P_{\mathrm{Lm}: \mathrm{EaR}} \cdot P_{\mathrm{T}: \mathrm{EaR}} \cdot V_{\mathrm{EaR}: \mathrm{Lm}} \cdot A_{\mathrm{EaR}}\right)$

where, $\mathrm{RD}_{\mathrm{EaR}}$ is the direct risk to the element at risk, $H_{\mathrm{m}}$ is
Table 3. Landslide hazard along the road in $\mathrm{T}_{50}$ years return period.

\begin{tabular}{lccc}
\hline \multirow{2}{*}{ Road section } & \multicolumn{3}{c}{ \# landslides/km } \\
\cline { 2 - 4 } & H-I & H-II & H-III \\
\hline SI (total length $10 \mathrm{~km})$ & 2.39 & 3.24 & 0.49 \\
SII (total length $14 \mathrm{~km})$ & 0.58 & 0.78 & 0.12 \\
\hline
\end{tabular}

H-I, H-II and H-III are the specific hazard related to landslide of M-I, M-II and M-III, respectively.

the hazard due to landslides of magnitude class " $m$ " (\#/km), $P_{\text {Lm:EaR }}$ is the probability of a landslide with magnitude " $m$ " reaching the element at risk $(0-1), P_{\mathrm{T}: \mathrm{EaR}}$ is the temporal probability of the element at risk to be exposed to a landslide of magnitude " $m$ " (0-1), $V_{\mathrm{EaR}: \mathrm{Lm}}$ is the vulnerability of the element at risk (degree of loss) caused due to the occurrence of a landslide of magnitude " $m$ " $(0-1)$, and $A_{\mathrm{EaR}}$ is the quantification (monetary value) of the element at risk. The specific risk is calculated per standard length of the road or railway line (e.g. per kilometre). The specific risk for different landslide magnitudes is added for each return period to generate the combined specific risk for a particular infrastructure element.

The direct specific risk to components of the road (the asphalt layers, culverts, side drains, etc.) and the railway line (gravel bed, rails, rake bars and sleepers) was estimated using Eq. (1). Other components of a railway line such as poles, cables are not present because the train is powered by a steam engine. The value of $P_{\text {T:EaR }}$ was taken as 1 as these elements are stationary objects. The value of $P_{\mathrm{Lm}: \mathrm{EaR}}$ was also taken as 1 because the infrastructure components are located below the cut slopes and landslides from these cut slope invariably reach them. The assessment of the vulnerability of the railway line and the road was based on the information obtained from historical events in the area. According to the JTC-1 guidelines (Fell et al., 2008), vulnerability is the degree of loss to a given element at risk within the area affected by a landslide, and is expressed on a scale from 0 (no loss) to 1 (total loss). Vulnerability can also be assessed by comparing the monetary value of damage with the present monetary value of the element at risk, as given in Remondo et al. (2008). In cases where the vulnerability is assessed by comparing the monetary loss per damaged section of the infrastructure by a landslide (e.g. US $\$ / \mathrm{m}$ ) with the actual construction costs, the vulnerability could theoretically be greater than 1 since the repair could cost more than constructing new infrastructure as it includes the additional cost of removing debris and also replacing damaged components. However, in this analysis the maximum value considered for the vulnerability is 1 (total loss). 
For the railway line a detailed analysis of the direct monetary losses due to landslides in the 16-year period from 1992 to 2007 was carried out. The damage data were taken from the railway slip register, which is available only for this period, and includes the type of damage such as the number of damaged rails, rake bars and sleepers, and the cost involved in the repair of the damaged structures. For the railway line, vulnerability $\left(V_{\mathrm{rl}}\right)$ was calculated as the ratio of the total restoration cost (US\$/m) of the damaged railway line due to a landslide of a given magnitude to the actual construction costs per unit length of the railway line (US $\$ / \mathrm{m}$ ) without taking into account the construction of bridges and the slope cutting. The railway bridges are constructed with a sufficient altitude above the channel beds so they are hardly ever damaged by landslides. The total restoration costs include the costs of removing landslide debris from the railway line and those of replacing the damaged components (i.e. rails, rake bars and sleepers). The cost of removing debris is the fixed contract rate which was obtained from the existing cleaning contracts (US\$ 5 per $\mathrm{m}^{3}$ ) and the cost of constructing a new railway line was determined to be US $\$ 110$ per $\mathrm{m}$ for the situation in 2007. The data were obtained from the Southern Railway office in Coonoor. The damage records indicate that the components of the railway line generally are not damaged by small slides from cut slopes (volume $<100 \mathrm{~m}^{3}$ ) and the restoration cost in such cases only involves the cost of removing debris. For slides of higher magnitude classes the restoration cost involves replacement of the damaged structures and the removing the debris. Therefore the vulnerability was taken as 1 for the occurrence of slides with magnitudes M-II and M-III.

The vulnerability of the road components was assessed based on the damage information obtained from the Highway office. The data indicate that landslides from cut slopes generally do not cause major structural damage to the road and the restoration cost mainly involves the cost of removing debris and minor repairs such as repair of parapet walls, culverts, etc. The road is a national highway approximately $10 \mathrm{~m}$ wide including an $8 \mathrm{~m}$ wide asphalt cover. It contains two bitumen layers of $75 \mathrm{~mm}$ (lower layer) and $20 \mathrm{~mm}$ (upper layer) thickness. The cost of constructing the lower layer (2007 situation) was US\$34 per $\mathrm{m}^{3}$ and for the upper layer US $\$ 4$ per $\mathrm{m}^{2}$ and the total cost of making a new road were US\$50 per $\mathrm{m}$, which includes only the cost of making the surface of the road and not the ground work, drainage work etc. The cost of removing debris from the road was determined from contracts to be US $\$ 0.7$ per $\mathrm{m}^{3}$. The records also indicate that not all of the debris of large landslides (M-III) was deposited on the road. In many instances these landslides had longer run-outs and part of the debris passed the road and reached the valley floor. Such slides caused damage to the retaining and parapet walls and also to the culverts. Similar to the railway line, the vulnerability of the road $\left(V_{\text {rd }}\right)$ was calculated as the ratio of the total restoration cost (US\$/m) to the actual construction costs of the road (US\$/m).
Table 4. Estimated vulnerability for elements at risk affected by a landslide.

\begin{tabular}{lccc}
\hline \multirow{2}{*}{ Type of Element at Risk } & \multicolumn{3}{c}{ Vulnerability } \\
\cline { 2 - 4 } & M-I & M-II & M-III \\
\hline \multirow{2}{*}{ Railway line } & Infrastructure & & \\
Road (Asphalt) & 0.5 & 1 & 1 \\
& 0.2 & 0.4 & 0.8 \\
Bus & Moving vehicle & & \\
Lorry & 0.01 & 0.1 & 0.8 \\
Car & 0.01 & 0.1 & 0.8 \\
Motorbike & 0.1 & 0.5 & 1 \\
Train & 0.5 & 0.8 & 1 \\
Person in a moving vehicle (probability of death) & \\
Bus & 1 & 1 & 1 \\
Lorry & 0.001 & 0.1 & 0.8 \\
Car & 0.001 & 0.1 & 0.8 \\
Motorbike & 0.01 & 0.1 & 1 \\
Train & 0.5 & 1 & 1 \\
\hline
\end{tabular}

Vulnerability for the railway line and the road for landslides of different magnitude classes are given in Table 4 . For the railway line the maximum vulnerability value was obtained for landslide of M-II and M-III and for the road it was for landslide of M-III. The vulnerability value decreases with the decrease in the size of a landslide. In the analysis we have used one vulnerability value for all landslides belonging to the same magnitude class. Theoretically, vulnerability can vary considerably with the decrease in landslide size (e.g. volume $<100 \mathrm{~m}^{3}$ ) but may not vary significantly for large landslides, which often result in a total damage of the element (e.g. $V=1$ ). In this study it was not feasible to calculate specific risk separately for all volumes, due to lack of information, and therefore we have assigned one vulnerability value for each magnitude class, which was estimated from the maximum volume in that class.

After obtaining all the required parameters i.e. hazard, vulnerability and amount, direct specific risk of the railway line $\left(R D_{\mathrm{rl}}\right)$ and the road $\left(\mathrm{RD}_{\mathrm{rd}}\right)$ was estimated for the 18 hazard scenarios. Tables 5 and 6 give an example of the specific loss per kilometre of the railway line and the road property, respectively for 50 -years return period. The total loss to the railway in $\mathrm{T}_{3}, \mathrm{~T}_{5}, \mathrm{~T}_{15}, \mathrm{~T}_{25}$ and $\mathrm{T}_{50}$ years return period is estimated as about US\$56 100; US\$201 700; US\$ 337300 ; US\$393700 and US\$472700, respectively. For the railway line, the loss in three years return time is estimated as about US\$ 56100 , which is less than the average annual loss of US\$ 83000 due to the maintenance of the railway track. The average annual loss was obtained from the past damage record for the period 1992 to 2007, which also includes other losses such as those from the daily maintenance of the track. 
Table 5. Direct specific risk per kilometre of the railway line.

\begin{tabular}{lcccc}
\hline \multirow{2}{*}{$\mathrm{km}$} & \multicolumn{4}{c}{ Loss (US\$/ $\mathrm{T}_{50}$ years) } \\
\cline { 2 - 5 } & H-I & H-II & H-III & Total \\
\hline 10 & 4532 & 36956 & 9297 & 50785 \\
11 & 5549 & 45247 & 11383 & 62179 \\
12 & 4918 & 40105 & 10089 & 55112 \\
13 & 3906 & 31849 & 8012 & 43767 \\
14 & 2610 & 21285 & 5355 & 29250 \\
15 & 2621 & 21373 & 5377 & 29371 \\
16 & 2280 & 18592 & 4677 & 25549 \\
17 & 2089 & 17035 & 4286 & 23410 \\
18 & 1823 & 14867 & 3740 & 20430 \\
19 & 1512 & 12330 & 3102 & 16944 \\
20 & 1407 & 11473 & 2886 & 15766 \\
21 & 1514 & 12348 & 3106 & 16968 \\
22 & 1847 & 15059 & 3788 & 20694 \\
23 & 1493 & 12173 & 3062 & 16728 \\
24 & 1517 & 12365 & 3111 & 16993 \\
25 & 1373 & 11194 & 2816 & 15383 \\
26 & 1193 & 9724 & 2446 & 13363 \\
Total & & & & 472692 \\
\hline
\end{tabular}

Table 6. Direct specific risk per kilometre of the road.

\begin{tabular}{lcccc}
\hline \multirow{2}{*}{ Section } & \multicolumn{4}{c}{ Loss (US\$/T 50 years) } \\
\cline { 2 - 5 } & H-I & H-II & H-III & Total \\
\hline SI & 239 & 3244 & 1469 & 4952 \\
SII & 58 & 785 & 355 & 1198 \\
\hline
\end{tabular}

The total loss to the road in $\mathrm{T}_{3}, \mathrm{~T}_{5}, \mathrm{~T}_{15}, \mathrm{~T}_{25}$ and $\mathrm{T}_{50}$ years return period is estimated as about US\$3900; US\$22 500; US\$ 44 400; US\$ 53500 and US\$ 66200 , respectively.

\subsection{Direct risk to vehicles}

Direct risk to a moving vehicle, i.e. a vehicle being hit by a landslide, depends on the probability $\left(P_{\mathrm{T}: \mathrm{EaR}}\right)$ of the vehicle being at the location of a landslide when it occurs. This probability $\left(P_{\mathrm{T}: \mathrm{EaR}}\right)$ was used to calculate the risk to a moving vehicle for a given return period using the following three expressions (adapted from AGS, 2000):

$$
\begin{aligned}
& \mathrm{RD}_{\mathrm{v}}=P\left(V_{\mathrm{m}}\right) \cdot V_{\mathrm{veh}: \mathrm{m}} \cdot A_{\mathrm{veh}} \\
& P\left(V_{\mathrm{m}}\right)=1-\left(1-P_{\mathrm{T}: \mathrm{EaR}}\right)^{\mathrm{Nr}} \\
& P_{\mathrm{T}: \mathrm{EaR}}=(\mathrm{ADT} \cdot L) /\left(24 \cdot 1000 \cdot S_{\mathrm{veh}}\right)
\end{aligned}
$$

where, $\mathrm{RD}_{\mathrm{v}}$ is the direct risk to a vehicle (US\$), $P\left(V_{\mathrm{m}}\right)$ is the probability of one or more vehicles being hit by a landslide with a magnitude " $m$ " $(0-1), V_{\text {veh }: m}$ is the vulnerability of the vehicle for a landslide of magnitude " $m$ " $(0-1), A_{\text {veh }}$ is the cost of the vehicle (US\$), $P_{\mathrm{T}: \mathrm{EaR}}$ is the temporal probability the vehicle at risk is exposed to a landslide of magnitude " $m$ " $(0-1), \mathrm{Nr}$ is the number of landslides of magnitude " $m$ ", ADT is the average daily traffic (vehicles per day), $L$ is the average length of the vehicle (m) and $S_{\text {veh }}$ is the speed of the vehicle $(\mathrm{km} / \mathrm{h})$.

The assessment of vulnerability of different types of moving vehicles (train, bus, lorry, car and motorbike) was carried out based on historic incidents where landslides hit moving vehicles. In one incident, near the Katteri farm, landslide debris from a landslide of magnitude class M-II pushed two moving cars across the road causing damage. The repair cost of each car was approximately as 50\% of its value. In 2006 a moving lorry was hit by a landslide of magnitude class M-III and the expected repair cost was more than $50 \%$ of the value of the lorry. The vulnerability of a moving vehicle depends on the speed and type of vehicle, the volume of landslide debris and the type of the transportation line. Theoretically a small, light weight vehicle such as a motorbike is more vulnerable than a big, heavy vehicle such as a bus or a truck. A train is vulnerable to a landslide because it takes some time to stop a moving train if the track or the train is hit by a landslide and derailment on a steep hill will certainly result in damage to the train. Vulnerability for different types of moving vehicles for landslides of different magnitude classes are given in Table 4. Landslides of magnitude class M-I and M-II are relatively small and expected to cause less damage (monetary loss) to big vehicles $(0.01-0.1)$ but can be disastrous for motorbikes $(0.5-0.8)$.

The parameters required for Eqs. (2-4) were obtained from historical incidents and field calculations. Though the speed limit on the road is $40 \mathrm{~km} / \mathrm{h}$, the average speed was measured as $26 \mathrm{~km} / \mathrm{h}$, based on the journey time that most of the vehicles took to cover the journey between the Kallar farm and Coonoor. The average speed of the train was measured as $11 \mathrm{~km} / \mathrm{h}$. The ADT values were taken from a toll gate register and the train time table. The ADT for buses, lorries, cars and motorbikes was obtained as 137, 309, 554, and 90 vehicles per day, and for the train it was two per day. The average length $(L)$ of a bus, lorry, car, motorbike and train was measured as $12,8,5,2$, and $55 \mathrm{~m}$, respectively. Using Eqs. (2-4), specific risk to a bus $\left(\mathrm{RD}_{\mathrm{b}}\right)$, lorry $\left(\mathrm{RD}_{1}\right)$, car $\left(\mathrm{RD}_{\mathrm{c}}\right)$, motorbike $\left(\mathrm{RD}_{\mathrm{mb}}\right)$ and train $\left(\mathrm{RD}_{\mathrm{t}}\right)$ was calculated for each hazard scenario.

Table 7 gives an example of the specific loss to a bus, lorry, car, motorbike and train due to landslides with 50-years return period. The cumulative loss to moving vehicles including train at any given time in $\mathrm{T}_{3}, \mathrm{~T}_{5}, \mathrm{~T}_{15}, \mathrm{~T}_{25}$ and $\mathrm{T}_{50}$ years return period is less than US $\$ 500$.

When calculating the risk to the property, it was assumed that all landslides of a given magnitude class in a given return period have the same volume which is used in the estimation 
Table 7. Direct specific risk for vehicles and train.

\begin{tabular}{lcccc}
\hline \multirow{2}{*}{ Elements at risk Type } & \multicolumn{4}{c}{ Loss (US\$ $/ T_{50}$ years) } \\
\cline { 2 - 5 } & H-I & H-II & H-III & Total \\
\hline Bus & 0 & 1 & 2 & 3 \\
Lorry & 0 & 1 & 1 & 2 \\
Car & 1 & 4 & 1 & 6 \\
Motorbike & 0 & 0 & 0 & 0 \\
Train & 190 & 259 & 39 & 488 \\
\hline
\end{tabular}

of the vulnerability. Since the vulnerability was estimated from the maximum volume in a given magnitude class, the calculated risk gives the maximum loss in a given return period.

\subsection{Direct risk to loss of life}

The risk of life or the annual probability of a person losing his/her life while travelling in a vehicle depends on the probability of the vehicle being hit by a landslide and the probability of death of the person (vulnerability) given the landslide impact on the vehicle. The vulnerability of commuter to a landslide depends on the type and size of the landslide, the speed and type of the vehicle, and whether the person is in the open or inside a vehicle (Wilson et al., 2005). It also depends on whether the debris directly hits the vehicle from the top or from the side. On 14 November 2006, a driver was killed and his associate was injured when a landslide of magnitude M-III hit a moving truck. The death of a person depends on many factors, including reflex and consciousness of the person at the time of impact, his/her physical condition, age and his/her perception about risk. In this analysis a single vulnerability value was taken for each magnitude class. Each magnitude class contains landslides with a range of volumes, for example M-I contains landslides ranging from 2 to $100 \mathrm{~m}^{3}$ and therefore their vulnerability also varies according to the volume of the landslide. The vulnerability is usually higher for landslides with larger volumes. For this analysis we have taken the maximum vulnerability for each magnitude class. The value was related to the maximum volume of the landslides in each magnitude class.

The vulnerability of people when a vehicle is hit by landslides of different magnitude classes is given in Table 4 . Landslides of magnitude classes M-I and M-II are relatively small and people travelling in big vehicles are less vulnerable than those travelling on motorbike (0.5-1).

The specific risk to people for a given return period was estimated using the following expression (adapted from AGS, 2000):

$R_{\mathrm{p}}=P\left(V_{\mathrm{m}}\right) \cdot V_{\mathrm{p}: \mathrm{m}}$

where, $R_{\mathrm{p}}$ is the annual probability of death $(0-1), V_{\mathrm{p}: \mathrm{m}}$ is
Table 8. Direct specific risk of the person most at risk using vehicle and train.

\begin{tabular}{lcccc}
\hline \multirow{2}{*}{$\begin{array}{l}\text { Mode of } \\
\text { travel }\end{array}$} & \multicolumn{4}{c}{ Loss of life (annual probability/T 50 years) } \\
\cline { 2 - 5 } & H-I & H-II & H-III & Total \\
\hline Bus & $1.7 \times 10^{-9}$ & $2.3 \times 10^{-7}$ & $2.8 \times 10^{-7}$ & $5.1 \times 10^{-7}$ \\
Lorry & $1.1 \times 10^{-9}$ & $1.5 \times 10^{-7}$ & $1.8 \times 10^{-7}$ & $3.3 \times 10^{-7}$ \\
Car & $7.0 \times 10^{-9}$ & $9.5 \times 10^{-8}$ & $1.4 \times 10^{-7}$ & $2.4 \times 10^{-7}$ \\
Motorbike & $1.4 \times 10^{-7}$ & $3.8 \times 10^{-7}$ & $5.8 \times 10^{-8}$ & $5.7 \times 10^{-7}$ \\
Train & $2.1 \times 10^{-5}$ & $2.9 \times 10^{-5}$ & $4.4 \times 10^{-6}$ & $5.6 \times 10^{-5}$ \\
\hline
\end{tabular}

the vulnerability of the individual (probability of death) given the landslide impact on the vehicle $(0-1)$. The parameter $P\left(V_{\mathrm{m}}\right)$ is estimated using Eqs. (3-4).

Using Eq. (5), the specific risk in terms of annual probability of the person most at risk losing his/her life by travelling in a bus $\left(R p_{b}\right)$, lorry $\left(R p_{1}\right)$, car $\left(R p_{c}\right)$, motorbike $\left(R p_{m b}\right)$ and train $\left(R p_{t}\right)$ was calculated for each hazard scenario. The analysis shows that the annual probability of the person most at risk losing his/her life by driving along the road in a hazard of $\mathrm{T}_{3}, \mathrm{~T}_{5}, \mathrm{~T}_{15}, \mathrm{~T}_{25}$ and $\mathrm{T}_{50}$ years return period is $1.2 \times 10^{-7}, 5.7 \times 10^{-7}, 1.1 \times 10^{-6}, 1.3 \times 10^{-6}$ and $1.7 \times 10^{-6} /$ annum, respectively. For rail users these values are $1.6 \times 10^{-5}, 2.4 \times 10^{-5}, 4.0 \times 10^{-5}, 4.7 \times 10^{-5}, 5.6 \times 10^{-5}$ per annum, respectively. Table 8 gives an example of the annual probability of death of the person most at risk travelling in a bus, lorry, car, motorbike and train due to landslides of 50-years return period.

The incidents pertaining to death of road users due to a landslide impact are not very frequent in the study area and also there is no recorded incident of a landslide hitting the train. The loss of life of people outside of vehicles was not evaluated because of lack of data and also because this does not happen frequently. The estimated annual probability of death of road and train users is also below the suggested tolerable individual risk for the existing cut slopes, which is $1 \times 10^{-4}$ /annum (AGS, 2000) in all return periods considered in the analysis. The total annual risk for the road users travelling by bus and car was also estimated. It was assumed that each bus and car carries an average of 50 and 6 persons, respectively. In a 3-years return period the annual risk (loss of lives) for both bus and car travellers is estimated as 0.0001 persons/annum. The low value of annual risk is the result of low number of vehicles per day.

\section{Estimation of indirect risk}

The indirect risk estimation requires two basic parameters: the hazard scenario that defines the blockage time of the transportation lines, and a socio-economic analysis of the study area to determine the most important activities in the area and their consequences to the society if disrupted. 
Every month on average 200000 tourists visit the Nilgiri area (Venugopal, 2004). The area is connected with Mettupalayam by a National Highway road (NH-67) and a railway. The NH-67 provides the shortest driving route between Coonoor and Mettupalayam. The alternate road via Kotagiri takes more time (about double) to reach Mettupalayam than by NH-67. The railway line is the other mode of travel but it also takes more time to reach Mettupalayam than travelling by NH-67 and it is mostly used by tourists. Tourists generally undertake the train journey once in their stay period either for coming to Coonoor or going back to Mettupalayam.

Besides tourism the Nilgiri is also known for several other businesses and services such as institutions, schools, tea production, etc. Every day a large number of people travel in and out of the Nilgiri for the purpose of work. The travellers from Mettupalayam and Coimbatore area usually take NH-67 for their journey. Also along NH-67 numerous shops and other businesses are located, which totally depend on travellers for their livelihood. Therefore, a blockage of NH-67 has higher indirect consequences to the society in general and to the local residents in particular, than a blockage of the railway.

We analyzed four types of indirect losses resulting from the temporal blockage of the transportation lines: additional fuel consumption; additional travel cost; loss of income to the local business; and loss of revenue to the railway.

At first step we identified the alternate driving routes (see Fig. 1) in case of the blockage of the main line. The traffic such as type of vehicles, intensity, tourist and local vehicles were estimated from data supplied from the revenue office at Coonoor and tollgate register of 2007. Estimates for revenue loss to the railway and average numbers of passengers were obtained from railway office at Coonoor. The types of business and their losses were obtained through participatory mapping i.e. the local residents were interviewed and questions were asked pertaining to their livelihood, type of business, monthly income, physical status, family details, number of dependents and any information regarding landslide damage and loss.

In the event of a blockage of the NH-67 road, a certain amount of travellers decide to take the alternate road via Kotagiri to reach Coonoor. Due to the availability of an alternate road, tourists and local people usually undertake their journey irrespective of the extra cost of the travel. For example in November 2006 the NH-67 was closed for a few days due to landslides and during the period the entire traffic was diverted via Kotagiri. The incident was highlighted in the newspaper and described as "Kotagiri-Mettupalayam road under strain" (Hindu, 2006). The road from Mettupalayam to Coonoor via Kotagiri covers an extra distance of $32 \mathrm{~km}$. To calculate loss due to the alternative driving route, it is assumed that tourist vehicles will cover this distance only once a day, while local Nilgiri vehicles will cover at least twice a day (i.e. onward and return). The mileage (fuel consumption per liter) also varies according to vehicle type, and for analysis the value was taken as $5,4,10$, and $30 \mathrm{~km} / \mathrm{l}$ for a bus, lorry, car and motorbike, respectively. The values were based on the official mileage rate fixed by the local transport office for the year 2007. The fuel cost was established as US\$ 0.8 per litre, which is the average value of diesel and petrol cost in the Nilgiri area in 2007. Indirect risk for additional fuel consumption for a given return period was calculated using the following expression:

$\mathrm{RI}_{\mathrm{FC}}=\left[(\mathrm{ARL} \cdot \mathrm{ADT} \cdot \mathrm{FC} \cdot \mathrm{TBT}) / \mathrm{M}_{\mathrm{V}}\right]$

where, $\mathrm{RI}_{\mathrm{FC}}$ is the indirect risk (monetary loss) due to additional fuel consumption by vehicles (US\$), ARL is the alternate road length $(\mathrm{km})$, ADT is the average daily traffic (vehicles per day), FC is the fuel cost (US\$/l), TBT is the traffic blockage time (day) and $\mathrm{M}_{\mathrm{V}}$ is the mileage of the vehicle $(\mathrm{km} / \mathrm{l})$.

TBT was obtained by dividing the total volume of debris $\left(\mathrm{m}^{3}\right)$ on the road by the average debris clearance rate $\left(\mathrm{m}^{3} /\right.$ day). The total volume of landslide debris in each return period was calculated from the hazard, which provides the number of landslides of magnitude classes M-I, M-II and M-III from cut slopes along the road. The number of landslides was multiplied by the median volume of each magnitude class to obtain the total volume of debris. The median value for each magnitude class was obtained from the landslide inventory, which is $20,200,1700 \mathrm{~m}^{3}$ for landslides of $\mathrm{M}-\mathrm{I}, \mathrm{M}-\mathrm{II}$ and M-III class, respectively. The average clearance rate along the road is $1100 \mathrm{~m}^{3}$ of debris per day. This value was estimated from the actual clearance rate, which is 20 lorries of debris per hour with $5 \mathrm{~m}^{3}$ of material per lorry.

Every day a large number of people travel in and out of Coonoor for work or for other purposes. In the event of road blockage they have to pay comparatively higher cost for tickets due to the longer travel distance, which is about US\$0.13 per journey. Every day on an average 120 local buses pass via Coonoor with an average capacity of 50 passengers. To calculate the additional cost of travel, we assumed that each bus carries at least 50 passengers who have to pay additionally US $\$ 0.13$ per journey. It may be possible that people may travel by other vehicles such as taxi, but in this area busses remain the main mode of travel and thus for analysis the other types of vehicles were not considered. Indirect risk for additional travel cost for a given return period was calculated using the following expression:

$\mathrm{RI}_{\mathrm{TC}}=\mathrm{ADC} \cdot \mathrm{CT} \cdot \mathrm{TBT}$

where, $\mathrm{RI}_{\mathrm{TC}}$ is the indirect risk (monetary loss) due to additional travel cost (US\$), ADC is the average commuters per day, CT is the cost of ticket (US\$) and TBT is the traffic blockage time (day).

Another adverse effect of the road blockage is on local business, which depends on road travellers on NH-67. These include shops, restaurants and hotels. In the Katteri area there are 11 business units and around Burliyar there are 35 units. The average loss of each business was obtained by 


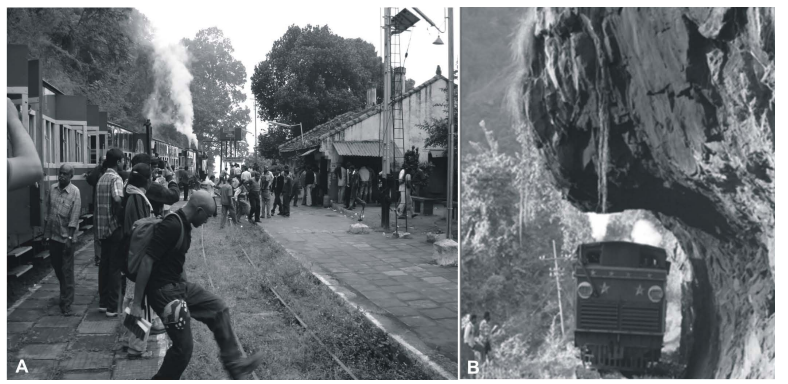

Fig. 3. Nilgiri toy train at Hillgrove railway station (A) and train crossing a half tunnel structure in a landslide zone $(\mathbf{B})$.

participatory survey. In Katteri, the average loss to restaurants, shops and hotels is approximately 75, 50, and 30\%, respectively and around Burliyar it is $100 \%$. The difference in the percentage loss is due to the location of the business. Katteri is located near Coonoor and is accessible by other local roads from west and north, but Burliyar is in the middle of the study section and hence it is totally cut-off during the blockage. Indirect risk for business for a given return period was calculated using the following expression:

$\mathrm{RI}_{\mathrm{B}}=\mathrm{NBT} \cdot \mathrm{ADI} \cdot P_{\mathrm{Loss}} \cdot \mathrm{TBT}$

where, $\mathrm{RI}_{\mathrm{B}}$ is the indirect risk (monetary loss) to business (US\$), NBT is the number of businesses, ADI is the average daily income from the business (US\$/day), $P_{\text {Loss }}$ is the probability of loss in income (0-1) and TBT is the traffic blockage time (day).

Another indirect loss is due to the blockage of railway line. The closure of rail traffic does not directly affect people economically but results in a revenue loss to the railway. It also results in an emotional loss to tourists who purposely visit the area for a train ride. The train is known as a "Nilgiri toy train" and runs between Coonoor and Mettupalayam twice a day. It is a small passenger train with a total sitting capacity of 200 people and also it is one of the major tourist attractions in the area (Fig. 3). Indirect risk to the railway department in a given return period was calculated using the following expression:

$\mathrm{RI}_{\mathrm{R}}=\mathrm{DIL} \cdot \mathrm{TBT}$

where, $\mathrm{RI}_{\mathrm{R}}$ is the indirect risk (monetary loss) to the railway department (US\$), DIL is the daily income loss (US\$/day) and TBT is the traffic blockage time (day).

The daily income includes revenue generated from the sale of tickets, which is on average US\$280/day. The traffic blockage time due to landslides was estimated from historical damage data obtained from the railway office. The data provided the total blockage time in different years (i.e. days when the railway line was closed for the traffic) and the amount of debris that were cleared from the railway line and the repair works that were carried out. The blockage time
Table 9. Loss due to additional fuel consumption.

\begin{tabular}{lcccc}
\hline Mode of travel & \multicolumn{4}{c}{ Loss (US\$/ T50years) } \\
\cline { 2 - 5 } & H-I & H-II & H-III & Total \\
\hline For local vehicle & & & & \\
Bus & 664 & 10030 & 12717 & 23411 \\
Lorry & 1515 & 22880 & 29010 & 53405 \\
Car & 614 & 9277 & 11763 & 21654 \\
Motorbike & 18 & 265 & 336 & 619 \\
For tourist vehicle & & & \\
Bus & 125 & 1881 & 2384 & 4390 \\
Car & 458 & 6916 & 8769 & 16143 \\
Motorbike & 32 & 488 & 618 & 1138 \\
\hline
\end{tabular}

Table 10. Indirect risk due to additional ticket cost.

\begin{tabular}{lcccc}
\hline Mode of travel & \multicolumn{4}{c}{ Loss (US\$/T 50 years) } \\
\cline { 2 - 5 } & H-I & H-II & H-III & Total \\
\hline Bus & 422 & 6367 & 8072 & 14861 \\
\hline
\end{tabular}

was found to vary from four to 134 days depending on the volume of debris and type of repair works needed for the restoration of the railway line. A scatter plot was generated between the total volumes of debris (in $\mathrm{m}^{3}$ ) on the railway line and total blockage time (days) in the period from 1992 to 2007. The relation has a power law distribution with power law exponent as 0.62 and constant as 0.31 . The coefficient of correlation was obtained as 0.65 . This relation was used to calculate the expected traffic blockage time due to landslides with a given return period. The traffic blockage time estimated to vary from 16 to 175 days depending on the total volume of material on the railway line.

Table 9 summarizes the result of the indirect loss for additional fuel consumption for the 50 -years return period. The total loss in $\mathrm{T}_{3}, \mathrm{~T}_{5}, \mathrm{~T}_{15}, \mathrm{~T}_{25}$ and $\mathrm{T}_{50}$ years return period amounts to US\$ 5200; US\$ 33700 ; US\$ 66 300; US\$ 80000 and US\$99000 to local Nilgiri vehicles, and US\$1100; US\$7400; US\$14 500; US\$17500 and US\$21700 to tourists vehicles, respectively. The total loss for both local and tourist vehicles, from 3 to 50 years, varies from US\$ 6300 to US\$ 120700 .

Table 10 summarizes the results of the additional travel cost estimated for a 50 years return period. The daily cost of additional tickets is around US\$780 for 6000 commuters estimated travelling each day in bus. Using this value, the total loss in $\mathrm{T}_{3}, \mathrm{~T}_{5}, \mathrm{~T}_{15}, \mathrm{~T}_{25}$ and $\mathrm{T}_{50}$ years return period was estimated as US\$ 780; US\$ 5000; US\$ 9900; US\$ 12000 and US\$14 800, respectively. 
Table 11. Indirect risk to local business.

\begin{tabular}{lcccc}
\hline Types of business & \multicolumn{4}{c}{ Loss (US\$/T 50 years) } \\
\cline { 2 - 5 } & H-I & H-II & H-III & Total \\
\hline At Katteri area & & & & \\
Hotel & 3 & 49 & 62 & 114 \\
Shops & 11 & 162 & 205 & 378 \\
Wine & 98 & 1477 & 1873 & 3448 \\
At Burliyar area & & & & \\
Shops & 38 & 571 & 724 & 1333 \\
\hline
\end{tabular}

Table 12. Indirect risk to the railway.

\begin{tabular}{ccccc}
\hline & \multicolumn{4}{c}{ Loss (US\$/T 50 years) } \\
\cline { 2 - 5 } & H-I & H-II & H-III & Total \\
\hline Railway & 7848 & 42495 & 49259 & 99602 \\
\hline
\end{tabular}

Table 11 summarizes the result of loss of business income around Katteri and Burliyar area due to landslides with 50 years return period. The total loss in $\mathrm{T}_{3}, \mathrm{~T}_{5}, \mathrm{~T}_{15}, \mathrm{~T}_{25}$ and $\mathrm{T}_{50}$ years return period was estimated as US\$200; US\$ 1300 ; US $\$ 2600$; US $\$ 3100$ and US\$3900, respectively for business located at Katteri and US\$ 70 ; US\$ 450 ; US\$ 900 ; US\$ 1100 and US\$1300, respectively for business located at Burliyar.

Table 12 summarizes the result of the revenue loss to the railway department for a 50 -years return period. The total loss in $\mathrm{T}_{3}, \mathrm{~T}_{5}, \mathrm{~T}_{15}, \mathrm{~T}_{25}$ and $\mathrm{T}_{50}$ years return period was estimated as US\$23 400; US\$ 58600 ; US\$ 80700 ; US\$ 88900 and US\$ 99600 , respectively.

The estimated loss to business is very low in comparison to other direct and indirect losses. However, for families involved in business with daily income of only few US dollars even the estimated loss of few hundred US dollars is highly significant.

\section{Total landslide risks}

The total landslide risk is the summation of all the specific risks related to landslides in an area including the indirect risks. It is obtained when the hazard for all landslide type and magnitude is multiplied with the expected losses for all different types of elements at risk (van Westen et al., 2006). In this study, total landslide risk of property loss was calculated by adding all direct specific risks and indirect risks of a given return period as given below:

$\mathrm{RT}_{\mathrm{EaR}}=\sum_{m=\mathrm{I}}^{\mathrm{III}}[\mathrm{RD}+\mathrm{RI}]=\sum_{m=\mathrm{I}}^{\mathrm{III}}\left[\left(\mathrm{RD}_{\mathrm{rl}}+\mathrm{RD}_{\mathrm{rd}}+\mathrm{RD}_{\mathrm{b}}+\mathrm{RD}_{\mathrm{l}}\right.\right.$
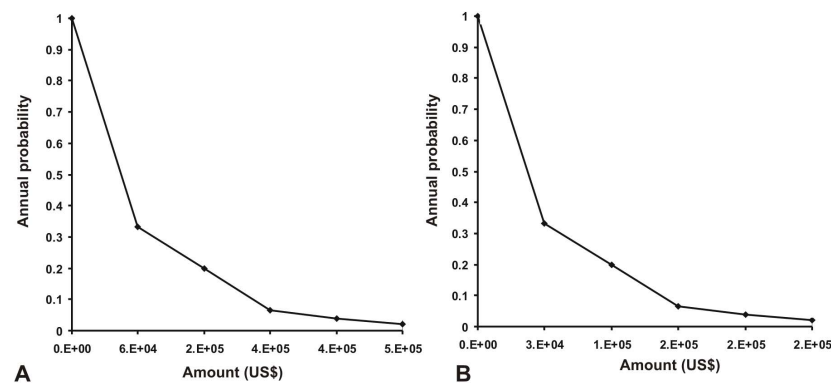

Fig. 4. Risk curve for total direct risk (A) and total indirect risk (B), expressed in monetary value (US\$).

$$
\left.\left.+\mathrm{RD}_{\mathrm{c}}+\mathrm{RD}_{\mathrm{mb}}+\mathrm{RD}_{\mathrm{t}}\right)+\left(\mathrm{RI}_{\mathrm{FC}}+\mathrm{RI}_{\mathrm{TC}}+\mathrm{RI}_{\mathrm{B}}+\mathrm{RI}_{\mathrm{R}}\right)\right]
$$

where, $\mathrm{RT}_{\mathrm{EaR}}$ is total risk in monetary loss (US\$).

The total landslide risk for the loss of life, $\mathrm{RT}_{\mathrm{p}}$ expressed as number of people per annum was calculated by adding all direct specific loss of lives, as given below:

$\mathrm{RT}_{\mathrm{p}}=\sum_{m=\mathrm{I}}^{\mathrm{III}}\left[\mathrm{R}_{\mathrm{pb}}+\mathrm{R}_{\mathrm{pl}}+\mathrm{R}_{\mathrm{pc}}+\mathrm{R}_{\mathrm{pmb}}+\mathrm{R}_{\mathrm{pt}}\right]$

The output of the result of the total monetary loss was displayed as a risk curve, containing the relation between hazard with different annual probabilities and the corresponding total losses. The area under curve gives the average annual loss.

The total indirect loss resulting from the traffic interruption of the road and the railway line by landslides in $T_{3}, T_{5}$, $\mathrm{T}_{15}, \mathrm{~T}_{25}$ and $\mathrm{T}_{50}$ years return period is around US $\$ 30840$; US\$ 106560; US\$ 175100 ; US\$ 202700 and US\$240 500, respectively and the total direct loss is around US\$60000; US\$2 24 200; US\$381 700; US\$ 447300 and US\$ 539000 , respectively. Thus, the total loss, including both direct and indirect losses, in $\mathrm{T}_{3}, \mathrm{~T}_{5}, \mathrm{~T}_{15}, \mathrm{~T}_{25}$ and $\mathrm{T}_{50}$ years return period amounts to US\$90 840; US\$ 330760 ; US\$ 556800 ; US\$ 650000 and US\$779 500, respectively.

Similarly, the total annual risk (loss of lives), in case of road vehicles and trains in which commuters are travelling are hit by landslides, is found to vary from 0.006 person/annum (in $\mathrm{T}_{3}$ years return period) to 0.02 person/annum (in $\mathrm{T}_{50}$ years return period).

Figure 4a displays the risk curve for total direct losses (US\$) and Fig. 4b for total indirect losses (US\$). The total indirect loss in different return periods is approximately $47 \%$ less than the total direct loss. The average annual total loss, including both direct and indirect losses, is estimated as about US\$35000. 


\section{Uncertainty and sensitivity analysis}

Inputs into the risk estimation are not precise but usually contain parameters having some degree of uncertainty, which may or may not be of considerable significance (Bell and Glade, 2004). Due to the uncertainty in input factors, the resulting risk values also indicate a considerable uncertainty. However, for landslide risk assessments it is not always practical to model uncertainties but it is possible to do sensitivity analysis by considering the effects of different assumed values for the inputs (Fell et al., 2005).

A qualitative estimate of uncertainties in different phases of the risk analysis is documented in Bell and Glade (2004). In this study, medium to very high uncertainty is associated with the hazard estimation and this is due to the limitation of the model, its basic assumption and insufficient data, particularly along the road. The Gumbel distribution used for estimating hazard on cut slopes is applied to extend the available data and hence predict the likely frequency of occurrence of landslides. Given adequate landslide records, the method will show that landslides of certain number may, on average, be expected annually or every 10 years or every 100 years and so on. It is important to realize that these extensions are only as valid as the data used and uncertainty will be high if extrapolation is done more than twice the length of the available time series. In this study, we estimated probability only up to 50 -years return period, which is slightly more than twice the record length available for the study. The important consideration in using results of Gumbel statistics is from the non-cyclical nature of landslide events, which further induce uncertainty in the hazard analysis. The 50-year return period (i.e. the number of landslides that will occur on an average once in 50 years) may occur next year or not for 100 years or may be exceeded several times in the next 50 years. In spite of the uncertainty, the result can be of great value in the interpretation and assessment of direct and indirect risk in specific time periods.

In the vulnerability estimation, the degree of uncertainty varies with landslide magnitude and the type and characterises of the elements at risk. For elements considered in this study, the vulnerability is not sensitive to large volume i.e. M-III $\left(>10^{3} \mathrm{~m}^{3}\right)$ and the uncertainty is low. For M-III, the vulnerability value for all elements at risk is either 0.8 or 1 (total damage) and therefore any further increase in the volume have no major affect on the vulnerability. But for small volume, especially M-I, the uncertainty is very high. The vulnerability for most of the elements decreases rapidly with the decrease in the landslide volume below $100 \mathrm{~m}^{3}$ and becomes insignificant for extremely small landslides. The use of single vulnerability value for M-I tends to overestimate the risk particularly in case when all expected landslides are of the size less than $100 \mathrm{~m}^{3}$.

Uncertainty in the risk analysis is also from the assumption that all landslides in a given magnitude class are of same size, which may not hold always. The assumption was used in the estimation of risk where typical loss from one landslide was multiplied by the total number of landslides per unit length.

The major source of uncertainty associated with the indirect risk is from the estimation of traffic blockage time (TBT), which is the most important parameter. TBT is highly sensitive to the amount of debris and its value changes significantly with the change in the total landslide volume. In the indirect risk analysis, loss was estimated on a daily basis and the value was then multiplied by TBT to obtain the total loss. Thus, any uncertainty in the estimation of TBT will result in high to very high uncertainty in the risk.

A sensitivity analysis of TBT and the resulted risk was carried out using different landslide volume. When the upper limit volume of class M-I $\left(10^{2} \mathrm{~m}^{3}\right)$ and M-II $\left(10^{3} \mathrm{~m}^{3}\right)$, and the maximum recorded volume of M-III $\left(3200 \mathrm{~m}^{3}\right.$ for railway and $5200 \mathrm{~m}^{3}$ for road) was considered, the estimated TBT was 251 days for the railway line and 6 days for the road and total indirect loss was about US\$118000 due to landslides with 3-years return period. But when the median value of landslide volume was taken for each magnitude class, the TBT was estimated as 110 days for the railway line and 2 days for the road and total indirect loss was about US\$ 30840 due to landslides with 3 -years return period. The analysis shows that the indirect risk, which directly depends on TBT, is highly sensitive to landslide volume and TBT.

Beside volume, many other parameters also induce uncertainty in the estimation of both direct and indirect risk and therefore it is recommended by IUGS Working Group on Landslides - Committee on Risk Assessment (1997) that final results of risk should be treated as relative results and not as absolute ones. Table 13 lists the important factors along with a rough qualitative estimation of the degree of uncertainty, the reason for uncertainty and its significance or effect in the final risk results.

\section{Discussion and conclusions}

The methods allowed us to estimate landslide risk quantitatively along a road and the railway line of Nilgiri area. The hazard model expressed as the number of landslides of a given magnitude class per kilometre of cut slopes was appropriate for determining both direct and indirect risk. The number provided the frequency of landslides, which was used to calculate the amount of debris on the transportation lines. This further formed the basis for estimating the traffic blockage time and related indirect consequences, which was otherwise not possible.

The inventory indicates that the number of landslides that occurred from cut slopes varies from one to 25 per year per kilometre along the railway line. The occurrence of low frequency and high magnitude events (i.e. $>10$ landslides/annum/kilometre) was successfully modelled by the Gumbel distribution. The model provided the return period for all events, which further facilitated in deriving different hazard scenarios. Though it is possible to generate 
Table 13. Qualitative estimation of uncertainties inherent in input data and results of risk analysis.

\begin{tabular}{lll}
\hline Factor & Uncertainty & Reason \\
\hline Hazard & Medium-high & Limitation of the model, basic assumption, insufficient data. \\
Volume of landslides & Low-medium & Measured data in historical record. \\
Probability of volume & Medium-high & Uncertainties in input factors (rainfall intensity and landslide size distribution). High \\
Vulnerability & Medium $\left(V_{\mathrm{rl}}\right.$ and $\left.V_{\text {rd }}\right)$ & Calculated from historical data. \\
& High-very high & Insufficient data, subjectivity, model assumption, lack of research. \\
Value of elements & Very low & Detailed information. \\
ADT & Medium & Insufficient data, seasonal and temporal variation. \\
Number of persons & Medium & No official data. \\
TBT & High-very high & Model sensitivity, incomplete information. \\
Resulting risk & High & Uncertainties in input factors. \\
\hline
\end{tabular}

numerous hazard scenarios, the actual number should depend on the best definition of a loss curve. The Gumbel distribution allows to estimate the probability for any number of return periods. In this study we estimated probability only up to a 50-years return period, which is slightly more than twice the record length available for the study. The records also indicate that landslides occur frequently in the area and therefore it was prudent here to consider scenarios based on lower return period i.e. 1,3 , and 5 years.

The availability of damage records of the transportation lines facilitated the calculation of vulnerability for the railway line and the road. The assessment of vulnerability for loss of life was subjective but based on historic incidents. Due to the unavailability of well documented examples of vulnerability of different types of vehicles such as a bus, lorry, car or motorbike and persons travelling in them, we were not able to compare our results with established ones. Only the vulnerability range of a person travelling in a car was comparable to the vulnerability values given in Wilson et al. (2005), which are 0.01 for debris of $30 \mathrm{~m}^{3}, 0.1$ for debris of $300 \mathrm{~m}^{3}$ and 1 for debris of $3000 \mathrm{~m}^{3}$.

To calculate the risk to life, the assumptions was made that the death probability is calculated only for accidents caused by the direct impact of landslide debris on a moving vehicle (both vehicle and landslide are moving). It is assumed that traffic is uniformly distributed in time. The evaluation of landslide risk to vehicles is also affected by uncertainties. The analysis was performed by considering average daily traffic values (ADT). During rush hours or during the weekends the traffic is heavier (and risk is higher), whereas during the night, traffic is lighter (and risk is lower). Instead of the posted speed limit, a calculated average speed was used in the analysis and the traffic was assumed to be constant and continuous. The unexpected stoppage of a vehicle is not considered as it is extremely difficult to model it. The analysis also did not consider which side of the road the vehicle is travelling on, although the position of a vehicle with respect to the debris slide affects the risk. In this case the asphalt road is only $8 \mathrm{~m}$ wide and vehicles generally move towards the valley side for better turning and visibility. Lastly, the analysis does not consider the possibility that a vehicle can run into debris that has fallen onto the road. The total road length is $24 \mathrm{~km}$ and information on landslide or debris fallen on the road is quickly transmitted by local people or police check posts located at Burliyar and Katteri area. In case of landslides, all traffic is diverted via Kotagiri (alternate driving route) and therefore there is less possibility of vehicles running into the landslide debris blocking the road.

Indirect risk due to traffic interruption can include risks such as social, economic and emotional, which are difficult to quantify. Quantification of other risks such as delays to the transportation of goods, disruption to non working people, loss of working hours, unsatisfied tourists due to non availability of the train service and loss of reputation from longer blockage periods were not attempted because the estimation of these effects is beyond the scope of this study.

The estimation of direct risk is more straightforward than the indirect losses. An indirect loss to someone could be of advantage to others, for example a fuel shop located on an alternative route may earn more due to road blockage and additional fuel consumption, similarly a transport company can earn profit through additional ticket costs and local vendors by increasing the price of commodities. It is rightly pointed out by researchers such as van Westen et al. (2006) that the risk formula looks deceptively simple, but once put into practice it quickly turns out to be very complicated and a lot of aspects need to be taken into account which are often difficult to evaluate.

For this study the estimated risk to life calculated for the road and train users are found to be below the tolerable limit based on the criteria given by AGS (2000). However, these criteria may not be applicable in India, in general and in the Nilgiri area, in particular and the boundary limits of the tolerable or intolerable risk may be different. At present there are no landslide risk tolerance criteria available in India and thus, the future work should focus on the development of one such criteria otherwise the assessment of risk is meaningless.

The results show a low risk to train users but every attempt should be made to keep the risk as low as possible. Risk reduction is technically feasible along the entire railway line 
by means of slope treatment works. Another risk mitigation strategy is to reduce the probability of a train being below a landslide when it occurs, for example, closing the railway line during periods of heavy rain. This will lead to a temporary loss of revenue to the railway but such loss may be worth accepting when there is a greater risk of losing lives in an accident. At present the railway authority reduces the risk to train users by closing the railway line during the periods of heavy rain. The estimated risk will help to perform the cost-benefit analysis of these risk mitigation strategies and to formulate the cost effective measures to be adopted in order to reduce landslide risk along the transportation lines.

Acknowledgements. We acknowledge the help of Southern Railway, Geo-technical Cell and Tea Estates of Coonoor, Tamilnadu, India for the relevant data and support. The research was carried out under the United Nations University- ITC School on Disaster Geo-Information Management (www.itc.nl/unu/dgim).

Edited by: F. Luino

Reviewed by: S. Sterlacchini, F. Lindenmaier, and

another anonymous referee

\section{References}

AGS, Australian Geomechanics Society and Sub-committee on landslide risk management: Landslide risk management concepts and guidelines, Aust. Geomech., 35(1), 49-92, 2000.

Bell, R. and Glade, T.: Quantitative risk analysis for landslides Examples from Bldudalur, NW-Iceland, Nat. Hazards Earth Syst. Sci., 4, 117-131, doi:10.5194/nhess-4-117-2004, 2004.

Bonachea, J., Remondo, J., Gonzalez-Diez, A., Diaz de Teran, J. R., and Cendrero, A.: Landslide risk modelling: an experience in northern Spain, in: Landslide Processes: from geomorphologic mapping to dynamic modelling, edited by: Malet, J. P., Remaitre, A., and Bogaard, T., Strasbourg, European Centre on Geomorphological Hazards (CERG), ISBN 2-95183317-1-4, 259-264, 2009.

Budetta, P.: Risk assessment from debris flows in pyroclastic deposits along a motorway, Italy, B. Eng. Geol. Environ., 6, 293301, 2002.

Bunce, C. M., Cruden, D. M., and Morgenstern, N. R.: Assessment of the hazard from rockfall on a highway, Can. Geotech. J., 34, 344-356, 1997.

Coe, J. A., Michael, J. A., Crovelli, R. A., and Savage, W. Z.: Preliminary map showing landslide densities, mean recurrence intervals, and exceedance probabilities as determined from historic records, Seattle, Washington, USGS Open-File report 00-0303, http://pubs.usgs.gov/of/2000/ofr-00-0303, cited on 15 July 2008, 2000.

Dai, F. C. and Lee, C. F.: Frequency-volume relation and prediction of rainfall-induced landslides, Eng. Geol., 59, 253-266, 2001.

Dai, F. C., Lee, C. F., and Ngai, Y. Y.: Landslide risk assessment and management: an overview, Eng. Geol., 64, 65-87, 2002.

Fell, R., Ho, K. K. S., Lacasse, S., and Leroi, E.: A framework for landslide risk assessment and management, in: Landslides Risk Management, edited by: Hungr, O., Fell, R., Couture, R., and Eberhardt, E., Taylor and Francis, London, 3-26, 2005.
Fell, R., Corominas, J., Bonnard, C., Cascini, L., Leroi, E., and Savage, W. Z.: Guidelines for landslide susceptibility, hazard and risk zoning for land use planning, Eng. Geol., 102, 85-98, 2008.

Glade, T. and Crozier, M. J.: The nature of landslide hazard and impact, in: Landslide hazard and risk, edited by: Glade, T., Anderson, M. G., and Crozier, M. J., Wiley, London, 43-74, 2005.

Gumbel, E. J.: Statistics of Extremes, Columbia University Press, New York, 1958.

Guzzetti, F.: Landslide fatalities and the evaluation of landslide risk in Italy, Eng. Geol., 58(2), 89-107, 2000.

Guzzetti, F. and Reichenbach, P.: Rockfall hazard and risk assessment along a transportation corridor in the Nera Valley, Central Italy, Environ. Manage., 34(2), 191-208, 2004.

Guzzetti, F., Reichenbach, P., Cardinali, M., Galli, M., and Ardizzone, F.: Probabilistic landslide hazard assessment at the basin scale, Geomorphology, 72, 272-299, 2005.

Hindu: Kotagiri-Mettupalayam road under strain, http://www. thehindu.Com/2006/11/16/stories/2006 \1\11611850100.htm, cited on: 27 August 2009, 2006.

Hungr, O., Evans, S. G., and Hazzard, J.: Magnitude and frequency of rock falls along the main transportation corridors of southwestern British Columbia, Can. Geotech. J., 36, 224-238, 1999.

IUGS Working Group on Landslides - Committee on Risk Assessment: Quantitative assessment for slopes and landslides - The state of the art, in: Landslide risk assessment, edited by: Cruden, D. M. and Fell, R., A.A. Balkema, Rotterdam, 3-12, 1997.

Jaiswal, P. and van Westen, C. J.: Estimating temporal probability for landslide initiation along transportation routes based on rainfall thresholds, Geomorphology, 112, 96-105, 2009.

Jaiswal, P., van Westen, C. J., and Jetten, V.: Quantitative assessment of landslide hazard along transportation lines using historical records, Landslides, under review, 2010.

Luino, F.: Sequence of instability processes triggered by heavy rainfall in northwestern Italy, Geomorphology, 66, 13-39, 2005.

Remondo, J., Bonachea, J., and Cendrero, A.: Quantitative landslide risk assessment and mapping on the basis of recent occurrences, Geomorphology, 94, 496-507, 2008.

Seshagiri, D. N. and Badrinarayanan, B.: The Nilgiri landslides, GSI Misc Pub No. 57, 1982,

Schuster, R. L. and Fleming, R. W.: Economic losses and fatalities due to landslides, Bull. Assoc. Eng. Geol., 23, 11-28, 1986.

Varnes, D. J.: Landslide Hazard Zonation: A Review of Principles and Practice, UNESCO, Daramtiere, Paris, 61 pp., 1984.

van Westen, C. J., Asch, T. W. J., and Soeters, R.: Landslide hazard and risk zonation-why is it still so difficult?, Bull. Eng. Geol. Env., 65, 67-184, 2006.

Venugopal, D.: Development-Conservation Dilemma in the Nilgiri Mountains of South India, J. Mt. Sci., 1(1), 74-80, 2004.

Wilson, R. A., Moon, A. T., and Hendrickx, M.: Application of quantitative risk assessment to the Lowrence Hargrave Drive Project, New South Wales, Australia, in: Landslides Risk Management, edited by: Hungr, O., Fell, R., Couture, R., and Eberhardt, E., Taylor and Francis, London, 589-598, 2005.

Zezere, J. L., Oliveira, S. C., Garcia, R. A. C., and Reis, E.: Landslide risk analysis in the area North of Lisbon (Portugal): evaluation of direct and indirect costs resulting from a motorway disruption by slope movements, Landslides, 4, 123-136, 2007. 